\title{
The essential connection between epistemology and the theory of reference
}

\author{
Dickie, Imogen
}

\begin{tabular}{|l|l|}
\hline Date of deposit & $17 / 09 / 2019$ \\
\hline Document version & Author's accepted manuscript \\
\hline Access rights & $\begin{array}{l}\text { C } 2016 \text { Wiley Periodicals, Inc. This work has been made available } \\
\text { online in accordance with publisher policies or with permission. } \\
\text { Permission for further reuse of this content should be sought from } \\
\text { the publisher or the rights holder. This is the author created } \\
\text { accepted manuscript following peer review and may differ slightly } \\
\text { from the final published version. }\end{array}$ \\
\hline $\begin{array}{l}\text { Citation for } \\
\text { published version }\end{array}$ & $\begin{array}{l}\text { Dickie, I. (2016). The essential connection between epistemology } \\
\text { and the theory of reference. Philosophical Issues, 26(1), 99-129. }\end{array}$ \\
\hline $\begin{array}{l}\text { Link to published } \\
\text { version }\end{array}$ & https://doi.org/10.1111/phis.12084 \\
\hline
\end{tabular}

Full metadata for this item is available in St Andrews Research

Repository at: https://research-repository.st-andrews.ac.uk/

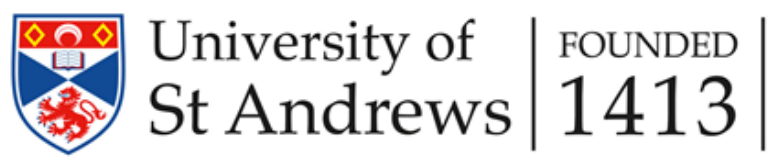




\section{The Essential Connection between Epistemology and the Theory of Reference}

Epistemology is the study of the conditions for knowledge. The theory of reference seeks to explain what makes it the case that singular terms, for example, proper names like 'Bertrand Russell' and demonstratives like 'this', stand for particular things. Recent philosophical tradition contains many instances where discussions in one of these fields draw on or illuminate the other: consider the alliance between causal theories of reference and causal theories of knowledge ${ }^{1}$, or the claim that understanding a genuinely singular term involves a special epistemic relation ('acquaintance') with its bearer ${ }^{2}$. However, this paper argues that the link between epistemology and the theory of reference is much more fundamental than the survey of extant proposals which I shall not prolong proceedings by attempting would suggest. A right theory of reference will be built around a principle bringing out the tie this paper's title advertises: there is an essential connection between epistemology and the theory of reference; this connection is a conduit through which influence flows irresistibly from each branch of inquiry to the other.

But before beginning the main discussion, I must say a little to clarify the 'theory of reference' part of its target.

The early twentieth century discussion of singular terms threw itself at three questions at once:

The question of formal semantic value - How should a singular term like 'Bertrand Russell' be treated by a theory laying out how the truth value of a sentence depends on contributions made by its constituents?

The question of aboutness-fixing ${ }^{3}$ - What makes it the case that the thought a speaker uttering a sentence like 'Bertrand Russell was a philosopher' intends to express is about a particular individual?

The question of linguistic reference - What makes it the case that, in the absence of special stage setting, a speaker uttering a sentence like 'Bertrand Russell was a philosopher' is rightly treated as expressing a thought about Russell?

For example, consider Russell's own descriptivism about proper names. This was all three of a theory of semantic value, a theory of aboutness-fixing, and a theory of linguistic reference. Russell said that a sentence containing a proper name is an abbreviated form of a sentence containing a description, so that it is in terms of the underlying, description-containing sentence that the initial sentence's inferential properties are to be explained. ${ }^{4}$ (This is a proposal about formal semantic value.) He said

\footnotetext{
${ }^{1}$ See for example Benacerraf 1973 p. 671.

${ }^{2}$ Russell 1956a. For a contemporary defence of this claim see Recanati 2010 . For a contemporary counterargument see Jeshion 2010.

${ }^{3}$ In the terms introduced in Kripke 1977, this is the question of what fixes the 'speaker's reference' of a token singular term.

${ }^{4} 1956$ b 242-3
} 
that a particular is introduced as relevant to the truth or falsity of the thought a subject using a proper name intends to express in virtue of the fact that the subject associates the name with a description the particular satisfies. ${ }^{5}$ (This is a proposal about aboutnessfixing.) And he said that speakers are using tokens of a type proper name as a name for the same individual - as a name that introduces the same individual as relevant to the truth or falsity of the thoughts expressed by sentences containing it - iff they associate the name with appropriately related descriptions. ${ }^{6}$ (This is a proposal about linguistic reference.)

However, one thread in the subsequent narrative has been the painful abandonment of this 'all at once' approach. It is a now familiar point that there are coherent frameworks which treat the three questions (almost) independently. ${ }^{7}$ And even explaining, let alone motivating, a particular stand on their exact connection would require too much philosophy to be attempted here. For this reason, I shall suppose no specific view of the relationship between the three target questions of the traditional theory of reference. Instead, I shall restrict the discussion to just one of them: the question of aboutness-fixing. So the essential connection I am going to bring out is, in the first instance, a connection between epistemology and the theory of aboutness-fixing. We should expect this initial connection to generate some further connections between epistemology and the theories of linguistic reference and formal semantic value. But I shall not begin to explore what these might be.

I shall also restrict the discussion further by focussing, for most of the paper, on what I shall call 'ordinary' thoughts about particulars. These are thoughts of the kinds standardly made available by perceptual links with ordinary material things; understanding of proper names used to refer to them; and grasp of mundane (nonscientific) descriptions. Here are three examples to illustrate the varieties of ordinary case:

Case 1 You are looking at an orange on a table in front of you. The viewing conditions are good; the situation devoid of causal or cognitive perversity: you are having an ordinary perceptual experience, caused by the orange in an ordinary way. You form beliefs you would express by saying things like 'That is round' and 'That is rolling'.

Case 2 You have not heard the name 'Aneurin Bevan' before. Somebody begins to explain who Bevan was: 'Aneurin Bevan was a British Labour Party politician. He was a long-standing member of parliament, and a cabinet minister in the 1940's and 50's. He was instrumental in the foundation of Britain's National Health Service.' Nothing about the situation leads you to doubt your informant's reliability. You take the utterances at face value, forming a body of beliefs you would express using 'Aneurin Bevan'.

Case 3 'Tremulous Hand' is used by scholars of medieval texts to refer to the otherwise unidentified author of around 50000 Thirteenth Century glosses in manuscripts. (Palaeographical analysis provides strong evidence that these glosses are the work of a single person with distinctive (tremulous and leftleaning) handwriting; all that is known about Tremulous Hand is what can be deduced from the glosses

\footnotetext{
51912 p 55

61912 p 57

${ }^{7}$ For example, consider Kent Bach's combination of views about proper names. Bach is a metalinguistic descriptivist about the formal semantic values of proper names (2002), a causalist about the aboutness of the thoughts we most often use them to express (2010), and denies that there is such a thing as linguistic reference (2006).
} 
themselves.) Finding out that the name is used in this way, and having ambitions to make your mark among the medievalists, you look for evidence for 'The author of the glosses was...' claims, and use them as a basis for building up a body of beliefs you would express using 'Tremulous Hand'

I shall call the kinds of thoughts illustrated by Cases 1-3 'perceptual demonstrative'; 'proper-name-based'; and 'description-based' thoughts respectively.

In making this suggestion, I do not suggest that the only cases of aboutness are ordinary ones - an unforgivably feudal stipulation given that everyday usage would describe us as thinking 'about' electrons; numbers; events; and systems of government; and as having thoughts about ordinary objects not made available in one of the ordinary ways. Rather, the suggestion is that thoughts about particulars should be regarded as a natural kind of which ordinary cases are the central exemplars. According to standard treatments ${ }^{8}$, an attempt to explain what it takes to belong to a specific natural kind should not start by taking the kind's boundaries for granted. It should start with central exemplars of the kind; try to provide an account of what they have in common at an appropriate level of explanatory depth; then use this account of the deeper commonality at the level of 'real essence' to decide where the kind's boundaries lie. The overall account of aboutness of which this paper is a component has this same structure. The suggestion is that we treat Cases $1-3$ as central exemplars of a cognitive natural kind. The first step in determining the boundaries of the kind is to find what is, in effect, its real essence - an account of how aboutness is fixed in these central cases. Given this account, we can ask where the kind's boundaries lie by asking to what extent features of the account of aboutness-fixing that has been developed for central cases applies to these other cases too.

The paper has three parts. $\S 1$ argues for the principle connecting epistemology and (the aboutness-fixing part of) the theory of reference that I want to propose. §2 gives a first indication of how this principle promises to illuminate the fields of inquiry it connects. $\S 3$ considers what I take to be the most urgent and illuminating objections.

\section{§1 REFERENCE AND JUSTIFICATION}

This section argues for a principle connecting epistemology and the theory of reference. The argument begins with two more basic principles, one connecting aboutness and truth, the other truth and justification:

Principle connecting aboutness and truth - If a belief is about an object, its truth or falsity depends on what the object is like. (If my belief that Jack has fleas is about my dog, it is true iff he has fleas.)

Principle connecting truth and justification (approximate version) - Justification is truth conducive; in general and allowing exceptions, the better your justification for a belief, the more likely its truth, so that if you form a justified belief, you will be unlucky if it is not true and not merely lucky if it is.

\footnotetext{
${ }^{8}$ Tracing their modern history to Kripke 1977 and Putnam 1975.
} 
The argument I am about to develop combines these two principles - one connecting aboutness and truth; the other truth and justification - to yield a direct connection between aboutness and justification: a principle which brings out the significance for accounts of aboutness of the fact that justification is truth conducive. Here is this third principle in preliminary and approximate form:

Principle connecting aboutness and justification (approximate version) - The beliefs a subject expresses using a singular term are about an object iff their means of justification converges on the object, so that, given how the beliefs are justified, the subject will be unlucky if they do not match the object and not merely lucky if they do.

To consolidate what this principle says, consider a situation where a telescope is focussed on some particular object. The fact that the telescope is focussed on the object does not guarantee that the information it delivers will match properties the object actually has. It does guarantee that this information will match the object unless some unlucky spoiler intervenes. The aboutness and justification principle treats thinking about objects as a kind of focus: the fact that a body of justified beliefs is about an object does not guarantee that the beliefs will match the object. It does guarantee that when this match fails the situation is somehow unlucky: where a justified belief is about an object, it will match the object unless some unlucky spoiler intervenes.

Of course, this approximate version of the principle cries out for clarification. At least partial clarification will have been achieved by the section's end.

The argument for the (clarified) aboutness and justification principle requires prior clarification of the truth and justification principle, which has itself been stated in mere approximate form: the author will not insult the reader by presenting an argument that relies on such terms as 'unlucky' and 'in general and allowing exceptions'. However, though I take the need to recognise some version of the truth and justification principle to be common ground ${ }^{9}$, the question of how to make this principle precise is a matter for inquiry in its own right, not to be addressed in a section of a paper on something else. So, though it is necessary to work with some precise version of the principle, the version I shall adopt is not one for which I shall attempt a comprehensive defence. Rather, it is the precisification I find most plausible. An alternative precisification of the truth and justification principle would necessitate adjustments in both the argument for the precisified aboutness and justification principle, and in this principle itself. However, I am confident both that something very like the argument to come, and something very like the principle it delivers will remain standing regardless of the fine-tunings that alternative versions of the truth and justification principle might require.

The precisified truth and justification principle with which I shall operate is most easily motivated using an example. Consider a commonplace belief: my belief that it is snowing outside, formed on the basis of what I see out the window and my prior knowledge that I am in a city whose miserable climate makes snow a frequent hazard at this time of year. In this case, my perceptual experience and prior knowledge give some

\footnotetext{
${ }^{9}$ If this suggestion worries you, note that it is consistent with all of the following: the possibility of justified false belief; the possibility that there are kinds of normative good order for belief that are not truth conducive; the possibility of a virtuous but unlucky subject who is always justified but never right; the possibility that the notion of justification should itself be explained in terms of that of knowledge.
} 
justification for believing that it is snowing outside. This justification - which we would usually regard as sufficing for the belief's rationality - rules out many 'not snowing outside' circumstances. (That is, the factors that contribute to the justification together entail that these circumstances are not actual.) But it is a familiar philosophers' niggle that the justification we ordinarily regard as securing rationality in this kind of case does not rule out all the circumstances where the belief is not true. For example, in the case at hand my justification does not rule out the possibility that it is fine outside and the drifting feathery white objects I can see are fake snowflakes being released by a film company. But, just as familiar as the niggle is the observation that worrying about arcane or unusual belief-not-true possibilities does not, and should not, hold up the path to belief. The cognitive resources available for the construction and maintenance of our belief systems are limited relative to the myriad ways a given belief might - just might fail to be true. It would be a poor use of these limited resources to seek justification that rules out even arcane, seldom-encountered not-p circumstances before forming the belief that $\mathrm{p}$. Instead, we should almost always ignore arcane possibilities, treating justification that rules out ordinary not-p circumstances as sufficient for rationality. This strategy will sometimes - in cases where an arcane or unusual not-p circumstance happens to be actual - leave us with false beliefs that meet the 'justified enough for rationality' standard. Such is the humble condition of belief-formers whose cognitive resources are eclipsed by the actual and potential complexity of their environment. ${ }^{10}$

The elements of the precisified truth and justification principle with which I shall operate can be read off this brief discussion of the 'bounded rationality' that characterises our cognitive lives. I shall suppose that a path to belief formation provides some justification for a belief iff it rules out a sufficiently large and varied range of ways the belief might fail to be true. I shall say that a belief is 'rational' (justified up to the point of rationality) iff it would have been an inappropriate use of cognitive resources to seek further justification - to expand the range of eliminated belief-not-true circumstances before forming it. And I shall say that a circumstance in which a belief is not true is 'rationally relevant' iff a belief formed on the basis of justification that does not exclude it is thereby irrational. Together these elements generate the following precisification of the truth and justification principle, which I shall call 'TRUTH AND JUSTIFICATION':

TRUTH AND JUSTIFICATION Justification that secures the rationality of a belief rules out every rationally relevant circumstance where the belief is not true. ${ }^{11}$

(I hasten to point out that I do not take myself to have proven this principle. This note ${ }^{12}$ discusses one obvious point where some people's preferred precisification of the claim that justification is truth conducive might depart from what I have proposed.)

\footnotetext{
${ }^{10}$ I intend to be endorsing the 'bounded rationality' framework of, for example, Bratman 1987.

${ }^{11}$ Compare Lewis 1999 p 36 - TRUTH AND JUSTIFICATION is parallel for the case of rational belief of Lewis's claim that $S$ knows that $p$ iff $S$ believes that $p$ and $p$ is true in every relevant circumstance uneliminated by S's evidence, though for the case of TRUTH AND JUSTIFICATION the 'relevance' is relevance to rational belief not relevance to knowledge. TRUTH AND JUSTIFICATION leaves open the possibility that standards ascribing rational belief might vary with features of the believer's, the ascriber's, or the assessor's context.

${ }^{12}$ I have endorsed an 'all-ist' account of the range of circumstances that must be eliminated by rationalitysecuring justification: rationality-securing justification for the belief that $\mathrm{p}$ must eliminate every rationally
} 
With TRUTH AND JUSTIFICATION in place, we can proceed to the argument for the precisified aboutness and justification principle. The principle itself is a biconditional connecting aboutness and a precisified notion of justificatory convergence. We can argue for the left-to-right direction of the biconditional (from aboutness to justificatory convergence) like this:

\section{Suppose}

$1 \mathrm{~S}$ 's belief that $<\alpha$ is $\Phi>^{13}$ is about $o$.

Add the aboutness and truth principle:

2 If S's belief that $<\alpha$ is $\Phi>$ is about an object, the belief is true iff that object is $\Phi^{14}$.

1 and 2 entail

$3 \mathrm{~S}$ 's belief that $<\alpha$ is $\Phi>$ is true iff $o$ is $\Phi$.

Add TRUTH AND JUSTIFICATION:

4 Justification that secures a belief's rationality eliminates every rationally relevant circumstance where the belief is not true.

\section{3 and 4 entail}

5 Justification that secures the rationality of the belief that $<\alpha$ is $\Phi>$ eliminates every rationally relevant circumstance where $o$ is not $\Phi$.

Having derived 5 from 1, we have one direction of our biconditional:

6 If S's $<\alpha$ is $\Phi>$ belief is about $o$, justification that secures the belief's rationality eliminates every rationally relevant circumstance where $o$ is not $\Phi$.

But what about the other direction, running from justificatory convergence to aboutness? I regret to say that the argument for this part of the biconditional is more intricate.

As a first step towards both seeing the need for additional intricacy and bringing out how the argument works, consider 'holistic' models of justification. According to such a model, a belief is never justified in isolation: any factor that contributes to

relevant not-p circumstance (circumstances that need not be eliminated are thereby rationally irrelevant). An obvious alternative is a 'most-ist' account: rationality-securing justification must eliminate most rationally relevant not-p circumstances. The choice between these options is too complex a matter to consider here.

13 ' $<\alpha>$ ' and ' $<\Phi>$ ' range over subject-place-occupying and predicate-place-occupying propositional constituents respectively.

14 ' $<\Phi>$ ' and ' $\Phi$ ' are braced together: $<\Phi>$ is a propositional constituent representing property $\Phi$. 
justifying it does so only in relation to an array of other beliefs, so that the factor really contributes to justifying a whole network of beliefs - the new belief together with the background array. It is widely accepted ${ }^{15}$ that justification in the construction of scientific theories does work like this. For example, consider how observation of a trail in a bubble chamber justifies a researcher's belief in the existence of some sub-atomic particle. Just the observation on its own could have no such impact: it is not as if the researcher has observed the particle itself! Rather, the observation makes its justificatory contribution against the background of the researcher's beliefs (a) in the scientific theory which predicts that such a trail will be generated in circumstances $\mathrm{X}$ iff the particle exists, and (b) that the experimental set-up has created circumstances X. And in fact the observation also adds to the researcher's justifications for the beliefs at (a) and (b) - if no trail had been observed, the researcher would have revisited first (b) then the more vulnerable elements of (a). So the observation is providing justification for belief in the particle's existence and the beliefs at (a) and (b) all at once.

Now suppose for the moment that all justification is 'holistic' in something like this sense. The hopelessness of trying to establish the kind of clean link between justificatory convergence and aboutness stated by the right-to-left direction of the aboutness and justification biconditional is an immediate result. Given the $\mathbf{1}-\mathbf{6}$ argument, we know that a factor that raises the level of justification across a network of beliefs about some range of particulars also raises the chances that more of the beliefs in the network will get right more of the properties of the objects they are about. But if all justification for the beliefs in a network is holistic - if every justificatory factor raises the chances that each belief will match the properties of the object it is about - the facts about justificatory convergence are themselves holistic, and leave the facts about aboutness for individual beliefs undetermined.

However, it is a careless philosopher who moves from confirmation holism about scientific theories to the conclusion that justification is holistic across the board. ${ }^{16}$ And in fact it is a now widespread observation that justification for what I have called ordinary beliefs is not 'holistic' in anything like the sense that seems applicable for scientific theories. Recall the cases of 'perceptual demonstrative' and 'proper name based' beliefs illustrated by Cases 1 and 2 respectively. Though there is room for wide-ranging debate about exactly how justification works in these cases, it is rare to find a contemporary philosopher espousing holism about either. And the 'bounded rationality' picture of our cognitive lives that is already in place lets us both consolidate just how implausible this extension of the holistic model would be, and bring out the outlines of what must be said instead.

To see this, consider a subject seeking to build an accurate account of some range of evolving particulars given a stream of information - reasonably generous but also very incomplete - as to how properties are distributed across this range at various times, and under the assumption that the information is fallible but generally reliable. (I take this to be our actual situation.) Because the information is incomplete, the subject must fill in

\footnotetext{
15 Following Duhem 1914

${ }^{16}$ Though I shall not try to argue for this diagnosis, I take the fashionability of this move in mid to late Twentieth Century epistemology to provide part of the explanation of how the principle I am about to defend has remained so long concealed.
} 
gaps in the picture the information provides. And because it is fallible, the subject must treat each incoming item as potentially to be re-interpreted or discarded.

In the broadest terms, there are two kinds of strategy by which this challenge might be addressed. The first is whole-heartedly holistic: interpret incoming information and fill gaps to achieve a picture meeting some holistic standard such as simplicity or coherence. The second strategy allows that there are beliefs which stand or fall together, but treats holistic connections as a check on belief formation, rather than as woven into the path to belief. A subject adhering to this second strategy will employ a policy of default acceptance of the deliverances of the information feed, treating this initial acceptance as revisable in the face of coherence requirements on the system as a whole.

Which strategy is optimal will depend on further details. Supposing that the distribution of properties across the objects from which the subject is receiving information in fact is simple and/or coherent, and given high enough capacities for storing information and calculating how one thing's probable $\Phi$-ness impacts another's possible $\Psi$-ness, the first, wholeheartedly holistic strategy might well prove effective. But this first strategy's feasibility falls off with decline in either the actual simplicity/coherence of the distribution of properties, or the capacities available for storage and calculation. Where these capacities are low relative to what would be required to execute the first strategy, then, provided that the information feed is sufficiently reliable, the other comes to the fore: the subject should take the incoming information at face value, while remaining sensitive to the possibility that beliefs formed by default uptake from the information feed will - on comparatively rare occasions require revision to maintain coherence across the picture as a whole.

With this contrast in place, I take it to be a matter of empirical fact that it is the second version of the challenge we ourselves face when in the business of forming beliefs like those in Cases 1 and 2, and the second kind of solution that we adopt. ${ }^{17}$ In each case, the incoming information feed is all of reliable, fallible, and gappy. Given much larger storage and information-processing capacities, it might be feasible to treat this incoming information as input to a wholeheartedly holistic strategy for constructing a picture of the world. But it is a matter of fact that the available capacities are restricted in just the way that makes wholehearted holism impracticable. And it is a matter of fact that the reliability of the incoming information feed is sufficient to favour the alternative 'default acceptance with sensitivity to defeaters' strategy instead.

In what follows, I shall suppose that each family of ordinary beliefs is associated with its own characteristic 'default acceptance with sensitivity to defeaters' justificatory strategy. For cases of perceptual demonstrative belief, like Case 1, the strategy is uptake from the information delivered through an attentional perceptual channel, with suitable sensitivity to factors that undermine perceptual reliability. For cases of proper-name based belief, like Case 2, it is uptake from a stream of testimony containing appropriately related token proper names and pronouns, with, again, suitable sensitivity to reliabilityundermining factors. For description-based cases like Case 3 it is use of a description to

\footnotetext{
${ }^{17}$ One source of empirical support for this claim comes from developmental psychologists' findings of the shift, as cognition matures, from 'high temperature' models of reasoning, in which the subject 'bounces around the space of hypotheses like a molecule bouncing around in a hot liquid' to 'low temperature' models, which are biased towards more usual outcomes, so are efficient generators of 'good enough' conclusions. Gopnik et al 2015 p 90.
} 
harvest information (for example, looking for evidence for $<$ The author of the glosses was $\Phi>$ beliefs, and marshalling the resulting $<\ldots$ was $\Phi>$ findings into a body of beliefs you would express using 'Tremulous Hand') with suitable sensitivity to the factors that suggest that you might be getting things wrong. I shall say that these justificatory strategies are 'proprietary' to their respective subclasses of ordinary belief. ${ }^{18}$

With the notion of proprietary justification in place, the argument for the right-toleft direction of the biconditional needs just one more ingredient. This is what I shall call the 'uniqueness lemma':

The uniqueness lemma - If the proprietary means of justification for a body of ordinary beliefs converges on object $o$, there is no $o^{*} \neq o$ for which this is also the case.

For perceptual demonstrative beliefs, the uniqueness lemma says that if there is some $o$ whose properties you will be unlucky to get wrong and not merely lucky to get right if you form a body of beliefs justified by uptake from an attentional perceptual channel, there is no $o^{*} \neq o$ for which this is also the case. For proper-name-based beliefs it makes the parallel claim for formation of a body of beliefs justified by uptake from a suitably unified stream of testimony. And for description-based beliefs it makes this claim about a body of beliefs anchored by the kind of means of justification associated with 'Tremulous Hand': looking for justification for $<$ The $\Psi$ is $\Phi>$, and combining the resulting $<\ldots$ is $\Phi>$ findings into a body of beliefs which you treat as about a single thing.

The case for the uniqueness lemma rests on a contingent fact. Let us say that ordinary objects are 'macroscopic duplicates' iff they share all their macroscopic observational properties, both intrinsic (like being square or blue) and relational (like being two feet away from an orange sphere). Then it is a contingent fact that if our world contains macroscopic duplication, macroscopic duplicates are located nowhere near one another. If the cup on the table in front of me has a macroscopic duplicate, this thing has the cup's same shape, size, and colour, and is located in the corner of a table qualitatively indistinguishable from this one at which someone qualitatively indistinguishable from me, standing in qualitatively identical relations to those in which I stand, types tokens of exactly these words. If this scene is unfolding anywhere, it is not on our planet or in our part of the universe: we know that the part of the universe with which we interact does not contain the kind of repetition and symmetry that this kind of duplication anywhere near us would require. However, it is consistent with everything we know that our own sector of space and time is one among multiple duplicate sectors, each repeating exactly the qualitative history of the others. If the cup and you and I have macroscopic duplicates, it is because this possibility - ineliminable by the factors that justify our beliefs about the empirical world - is actual: there is a region of space and time upon

\footnotetext{
${ }^{18}$ The notion of proprietary justification has precursors in Dummett's notion of canonical verification; Evans's notion of a 'controlling conception'; Campbell's notion of a 'dedicated' path to justification; and Recanati's notion of the 'special way of gaining information' associated with a mental file (see pp. 312-315 of Dummett 1978; pp. 177-179; p. 145 and p. 174 of Evans 1982; Campbell 1999; p. 157 of Recanati 2010; and pp. 34-38 of Recanati 2012).
} 
whose existence our ordinary empirical evidence is silent, but in which duplicates of us parallel our lives. ${ }^{19}$

Having noted this contingent fact, we can argue for the uniqueness lemma like this. The proprietary means of justification for a body of ordinary beliefs is a sub-species of ordinary empirical justification. But ordinary empirical justification is silent about the existence of objects in sectors of space-time other than our own. And the proprietary means of justification for a body of ordinary beliefs is just a species of ordinary empirical justification. It will, therefore, leave the existence or not of objects in other sectors a matter of chance. But in that case, if the proprietary means of justification for a body of beliefs converges on some object, this must be an object in our own sector. However, if this means of justification were to converge on two objects, they would have to be macroscopic duplicates (if $o$ and $o^{*}$ are not macroscopic duplicates, a means of forming $<\alpha$ is $\Phi>$ beliefs that reliably match $o$ 's properties will not also be a means of forming beliefs that reliably track $o^{*}$ 's) . But there is no macroscopic duplication within our own sector. So where proprietary justification converges, it converges uniquely. ${ }^{20}$

And now we can argue for the biconditional's right-to-left as follows:

1 Suppose that subject $\mathrm{S}$ is maintaining a body of ordinary beliefs whose proprietary means of justification converges on object $o$, so that if S forms only $<\alpha$ is $\Phi>$ beliefs whose rationality is secured by this means, in each case either $o$ is $\Phi$, or the situation involves some factor that makes it rationally irrelevant from the point of view of formation of the $<\alpha$ is $\Phi>$ belief.

2 There are three cases.

(a) The beliefs are about some $o^{*}$ other than $o$.

(b) They are about $o$.

(c) They are about nothing.

But materials already in place will let us establish 3:

3 The beliefs are not about some $o *$ other than $o$.

Suppose that $\mathbf{3}$ is false: S's beliefs as described in $\mathbf{1}$ are about some $o * \neq o$. But given the uniqueness lemma, proprietary justification for a body of beliefs can converge on only one object. And in the case described at 1 it converges on $o$. So it does not also converge on $o^{*}$. So 1, the uniqueness lemma, and the claim that S's beliefs are about some $o^{*} \neq 0$ entail that S's beliefs are about an object $\left(o^{*}\right)$ upon which their proprietary means of justification does not converge. And that contradicts the direction of the biconditional that we have already established: the claim that where there is aboutness there is justificatory convergence.

And we can also see the rough shape of an argument for 4:

\footnotetext{
19 This observation was a central ingredient in the 'puzzle about massive reduplication' introduced in Ch1 of Strawson 1959.

${ }^{20}$ I provide a more comprehensive version of this argument at Dickie $2015 \mathrm{pp}$ 65-72, and discuss complications arising from the 'problem of the many' at Dickie 2015 pp 27-34.
} 
4 The beliefs are not about nothing.

For suppose that $\mathbf{4}$ is false - the beliefs are about nothing. Again, we have already shown that where there is aboutness there is justificatory convergence. So to suppose S's beliefs as described at $\mathbf{1}$ about nothing is to suppose that wherever there is aboutness there is justificatory convergence, but that there is some extra condition on aboutness as well: where this condition is met, the subject's beliefs are about the object on which justification converges; in cases of justificatory convergence where the extra condition is not met, aboutness fails. But the claim that there is some such extra condition cannot be a mere stipulation: it must be sustained by an account of the explanatory work the extra condition is required to do. And it is very hard to see what this explanatory work might be.

$\mathbf{2}, \mathbf{3}$, and $\mathbf{4}$ entail

5 The beliefs are about $o$.

And having argued from $\mathbf{1}$ to $\mathbf{5}$ we have a connection running from justificatory convergence to aboutness:

6 Where the proprietary means of justification for a body of ordinary beliefs converges on $o$, the beliefs are about $o$.

The $\mathbf{1}-\mathbf{6}$ argument is valid. $\mathbf{2}$ is trivial. And if the uniqueness lemma is granted, the move to $\mathbf{3}$ is straightforward. The difficulty is at $\mathbf{4}$, for which we have, so far, only a rough and ready case. But for the sake of getting the proposal I want to make on the table, I shall treat this preliminary case for $\mathbf{4}$ as good enough to be getting on with, and upgrade it in $\$ 3.4$ below.

Now let us put the two halves of the argument together. We first established a necessary condition on aboutness in general ( 6 on p5):

If an $<\alpha$ is $\Phi>$ belief is about $o$, justification that secures the belief's rationality eliminates every rationally relevant circumstance where $o$ is not $\Phi$.

And the conclusion just established (6 immediately above) states a corresponding sufficient condition on aboutness for the special case of ordinary beliefs. Combining the two conclusions, and letting the less general claim drag the more general down with it, we get the full-dress version of the principle connecting aboutness and justification stated in preliminary form on p.3. I shall call the full-dress principle 'REFERENCE AND JUSTIFICATION':

REFERENCE AND JUSTIFICATION - A body of ordinary beliefs is about $o$ iff its proprietary means of justification converges on $o$ so that, for all $\langle\Phi>$, if $\mathrm{S}$ has proprietary rationalitysecuring justification for the belief that $\langle\alpha$ is $\Phi>$, this justification eliminates every rationally relevant circumstance where $o$ is not $\Phi$.

Here is a picture to consolidate what this principle says: 


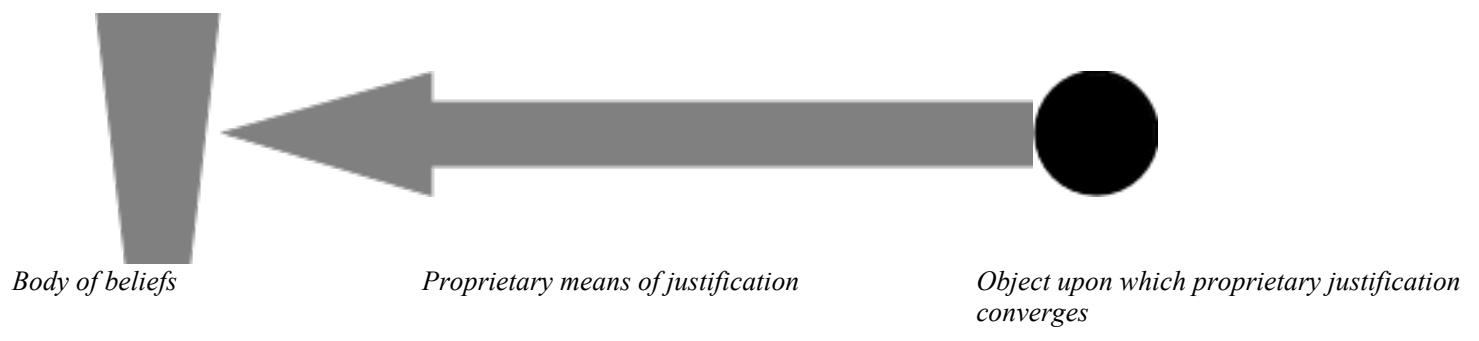

The file-shape at the left represents a body of ordinary beliefs. The arrow represents its associated proprietary means of justification: uptake from a perceptual link; uptake from an appropriately unified stream of testimony; moving to $<\alpha$ is $\Phi>$ given justification for believing < The $\Psi$ is $\Phi>$. REFERENCE AND JUSTIFICATION says that the body of beliefs is about $o$ iff $o$ is the object upon which its proprietary means of justification converges, so that, for all $\langle\Phi>$, if the subject has an $\langle\alpha$ is $\Phi>$ belief rationally justified by this means, either $o$ is $\Phi$, or the mismatch traces to some devious or unusual factor the subject was not rationally required to anticipate. ${ }^{21}$

There are many points of detail still to be addressed, and a number of objections will probably spring to the reader's mind. I shall discuss some objections, and in doing so fill in some details, in $\S 3$. But first I want to return to the promise made at the paper's outset: I promised to establish a principle that provides new insights into both the theory of reference and the problem set of traditional epistemology. The principle is now in place. It remains to sketch how it might be put to work in the theory of reference, on the one hand, and epistemology in the other. That is the task of $\S 2$.

\section{§2 New foundations for the theory of reference; new tools for epistemology}

This section gives a brief indication of how REFERENCE AND JUSTIFICATION promises to advance discussion in both the theory of reference and epistemology. I shall spend most of the section discussing the perceptual demonstrative and proper-namebased cases, returning to the description-based case at its close.

Recall that in the terms introduced on p3, 'perceptual demonstrative' thoughts are thoughts of the kind standardly made available by attentional perceptual links, and standardly expressed using 'this' or 'that'. 'Proper-name-based' thoughts are thoughts of the kind standardly made available by access to an appropriately unified stream of testimony. I shall consider how REFERENCE AND JUSTIFICATION changes the discussion of aboutness-fixing for these thoughts, then consider how it impacts their epistemology.

The dominant strand in attempts to explain aboutness-fixing in the perceptual demonstrative and proper-name-based cases forms a catalogue of appeals to candidate causal relations and 'because the object satisfies this description' conditions, with attempts to refute or refine proposals built around familiar gambits of counterexample and adjustment: that can't be the required causal condition because here is a case where

\footnotetext{
${ }^{21}$ Note that bodies of belief are being individuated functionally (by their proprietary means of justification and their internal unity relations) rather than by what they are about.
} 
intuition declares for aboutness but the proposed causal condition fails; this can't be the required description because here is a case where the subject's beliefs are about something other than the description's satisfier.

In hindsight, I think it is very obvious that this entire debate was taking place at the wrong level of explanatory depth. Even had the game of counterexample and adjustment enabled us to isolate causal or descriptive relations characteristic of each case - type relations tokens of which hold wherever there is perceptual demonstrative or proper-name based aboutness - we would still need reasons to think that these are relations that do aboutness-fixing work, rather than relations that happen to hold where and only where there is aboutness. But at the time of writing, the traditional, exampledriven discussion has failed even by the minimal criterion of having generated counterexample-proof suggestions as to what the causal, descriptive, or hybrid aboutnessfixing relations in the perceptual demonstrative and proper-name-based cases might be.

The REFERENCE AND JUSTIFICATION framework offers a unifying alternative to this traditional approach. REFERENCE AND JUSTIFICATION itself is neither a causalist nor a descriptivist principle. But it enables us to explain when a causal relation is doing aboutness-fixing work; when aboutness is descriptively mediated; and what causal and descriptive aboutness-fixing have in common. In the REFERENCE AND JUSTIFICATION framework, an aboutness-fixing relation is a relation of cognitive focus; a relation that makes available a means of justification such that the subject will be unlucky if beliefs whose rationality is secured by this means do not match what the object is like, and not merely lucky if they do. A causal aboutness-fixing relation is a causal relation which secures this result. A descriptively-mediated aboutness fixing relation is a relation of cognitive focus where the means of justification deploys the subject's grasp of a description. So REFERENCE AND JUSTIFICATION generates a new blueprint for accounts of perceptual demonstrative and proper-name-based aboutness-fixing. An account of perceptual demonstrative aboutness-fixing will explain how beliefs formed by uptake from an attentional perceptual link with an ordinary object are justified, and show how this justification converges on the attended thing. An account of aboutness-fixing for proper-name-based beliefs will answer the parallel questions for uptake from an appropriately unified stream of testimony: it will explain how the beliefs you form in a case like Case 2 ('Aneurin Bevan') are justified, and show how this justification converges on the bearer of your informant's uses of the name. Since attentional perceptual links and testimony links are both kinds of causal relation, both kinds of aboutness-fixing will be treated as involving a causal relation to the object. Whether they should also be regarded as involving descriptive relations will depend on the details of the justificatory story in each case - it will depend on whether the means of justification in Cases 1 and 2 rest on the subject's grasp of a descriptive condition. ${ }^{22}$

This sketch of how REFERENCE AND JUSTIFICATION offers a new start for accounts of perceptual demonstrative and proper-name-based aboutness-fixing also lets us begin to see how the neglected connection between aboutness and justification might illuminate traditional questions in epistemology. For perceptual demonstrative and proper-namebased belief are also at the heart of old and ongoing epistemological debates - the debates about how perception and testimony can be sources of knowledge. In each case,

\footnotetext{
${ }^{22} \mathrm{Ch} 4$ of Dickie 2015 discusses the perceptual-demonstrative case in much more detail. Ch 5 discusses the proper-name-based case.
} 
REFERENCE AND JUSTIFICATION generates a constraint on right accounts of justification that feeds straight into the epistemological discussion.

This constraint's potential for epistemological payoff can be illustrated using the traditional problem of deciding which typings of belief-forming methods count as epistemically relevant. Let us use the perceptual demonstrative case to bring out the traditional problem. There is a fact of the matter about the token path to belief formation in a specific case of perceptual demonstrative belief - this information-processing state precedes this one, which precedes this one, and so on. But a token path to belief formation may be assigned a type in myriad ways. In Case 1 as described, the beliefs are generated by uptake from an attentional perceptual link with an ordinary object. But what would count as forming a belief by the same method again? Does the relevant notion of 'sameness' require that beliefs formed by 'the same' method be formed just by uptake from a perceptual feed? Or must the perceptual feed also be attentional? If the perceptual feed must be attentional, is it a requirement that there be an ordinary object at the other end of the attentional link, or does attention to 'things' like ripples and shadows count as well? Is the relevant typing of methods date-sensitive, so that Case 1-type beliefs would count as formed by one method on Tuesdays and Thursdays, but another on other days of the week? (Surely not, but why not?) A token method may be typed in multiple ways. Any proposal appealing to type methods of belief formation must justify the choice of the favoured typing over the host of other candidates.

This problem first came to prominence as an objection to 'reductive reliabilist' views of knowledge and justification - views according to which whether a belief counts as justified or as knowledge is claimed to be explicable in terms of whether it is formed by a reliable method, with the notion of a 'reliable method' treated as explanatorily prior to those of 'knowledge', 'justification', and their cognates. For the reductive reliabilist, asking whether a belief is justified just is asking whether it is formed by a reliable method. And the question of whether a belief is formed by a reliable method cannot be answered simply by considering whether it is true. Even in asking this question, we are treating the belief as formed by a method that is a token of a repeatable type: the question is whether tokens of the type method produce true beliefs across a sufficiently wide and varied range of circumstances. ${ }^{23}$

But it is a familiar observation that stepping away from reductive reliabilism does not make the problem go away. For example, consider the widespread claim that there is a 'safety' requirement on knowledge: a true belief counts as knowledge only if the subject could not easily have been wrong in a similar case. ${ }^{24}$ A safety requirement is a requirement on how things could have gone differently given the same, or a sufficiently similar, means of belief formation. Would a sufficiently similar way of arriving at the belief that $p$, deployed in sufficiently similar circumstances, be sufficiently likely to generate truth? If 'No', the true belief that $p$ is unsafe, so not a case of knowledge. Many philosophers who are not reductive reliabilists endorse safety requirements. And anybody doing so must explain what counts as a 'sufficiently similar' path to belief formation. Though abandonment of reductionist ambitions widens the range of options available in answering this question, the problem of explaining why one typing should be preferred to others remains.

${ }^{23}$ For a canonical discussion of this objection to reductive reliabilism see Conee and Feldman 1998.

${ }^{24}$ Sosa 1999; Williamson 2000. 
Against this background, the previous section's proposal, with its appeal to the 'proprietary means of justification' characteristic of each class of ordinary belief, emerges as one of a large population of views all requiring non ad hoc grounds for treating a favoured typing of belief-forming methods as epistemically relevant. But the proposal also generates a new kind of consideration to add to the bit-by-bit account of what these non ad hoc grounds might be. ${ }^{25}$ In the broadest terms, this is because the proposal connects the old problem to a store of robust intuitions - intuitions about reference and reference failure - which can then be used to argue for the typing of methods that predicts and explains them.

Let us use the perceptual demonstrative case to add some detail to this line of thought. We already have one example involving essayed perceptual demonstrative thought in place - Case 1 (you are looking at an orange on the table in front of you...). Here are two others:

Case 4 - It seems to you that you are looking at a rectangular thing in the middle distance. You form the beliefs you would express by saying 'That is rectangular' and 'That is a few hundred feet away'. In fact, your experience as of a rectangular thing in the middle distance is caused by a freak combination of a speck on your glasses, a tree in the middle distance, and a barn on the horizon.

Case 5 It seems to you that you are looking at something round-ish moving slowing in the shadows. You think <It's round-ish and slow-moving; maybe it's a hedgehog $>$. In fact there is nothing there - the 'visual object' (in psychologists' terms ${ }^{26}$ ) that you are attending to is just a thickening in the general pattern of light and dark.

I take it that, just as Case 1 is a case of aboutness, Cases 4 and 5 are cases of aboutnessfailure: there are no objects the respective beliefs are about; in each case, when you find out your mistake you are likely to report it by saying 'There was nothing there after all'.

Now consider the typing of the token method of belief formation involved in Case 1 that was already supposed in $\S 1$ : the method is uptake of information delivered through an attentional perceptual channel. It is an empirical fact that this belief-forming method delivers beliefs that reliably match what the object is like iff it is an ordinary object behaving in ways usual for ordinary objects in our environment. As vision scientists often put the point, the perceptual system 'assumes' that it is dealing with ordinary objects behaving ordinarily in an ordinarily-configured space; its algorithms produce generally right results as long as this 'assumption' is true. ${ }^{27}$ So if we say that the method of beliefformation in Cases 1, 4, and 5 is uptake from an attentional channel in which the perpetual system has generated an information feed by responding to environmental cues in its standard ways (the ways it standardly responds in typical situations we encounter), and if we say that the 'rationally relevant' circumstances with respect to formation of a $<$ That is $\Phi>$ belief are those where the attended object behaves in ways that are usual for its category in the subject's environment, we get the results that seem intuitive across the range of cases. Case 1 is a case of aboutness because the means by which the beliefs are formed eliminates rationally relevant circumstances where the attended object does not

\footnotetext{
${ }^{25}$ For a recent contribution to this account see Comesana 2010.

${ }^{26}$ See for example Pylyshyn 2003 p 173. A 'visual object' is anything that is treated as an object by the visual system.

${ }^{27}$ Palmer 1999 p 313; Scholl 2002 Intro; Pylyshyn 2003 §3.1.1.
} 
have the relevant properties. Cases 4 and 5 involve aboutness failure because, given that the attended visual objects are not ordinary (they are not members of the category of ordinary objects; they are 'things' whose standard behaviours diverge wildly from what is standard for ordinary things), it will in fact be a matter of luck if a means of belief formation that rests on algorithms that suppose ordinariness get their properties right.

In contrast, if we had said just that the method is uptake from perception, we would not even have got the result that Case 1 is a case of aboutness. For mere uptake from a perceptual link is not a reliable means of generating beliefs that match objects in the environment (think about how unreliable are our guesses of the properties of objects in unattended peripheral vision - objects from which we are, nevertheless, receiving perceptual information). And if we said that the method was uptake from an attentional perceptual link with an ordinary object, the beliefs in Cases 4 and 5 would have counted as not formed by the same method as those in Case 1, so as not justified the same way, so we would not have end up with an account of aboutness-fixing in Case 1 which also explains why aboutness fails in Cases 4 and 5.

Of course, this brief discussion does not close off all possible alternative typings of the token methods by which various beliefs are formed. But I think I have said enough to show how the connection between epistemology and the theory of reference that I have proposed brings a new kind of consideration to addressing this traditional epistemological question.

I shall close the section by saying a little about the impact of REFERENCE AND JUSTIFICATION on right accounts of what I have called 'description-based thought' - the kind of thought illustrated by Case 3 on $\mathrm{p} 2$.

Here, again, REFERENCE AND JUSTIFICATION generates a blueprint for accounts of how aboutness is fixed: a body of description-based beliefs is about the object, if there is one, upon which its proprietary means of justification converges: the object whose properties the subject will be unlucky to get wrong and not merely lucky to get right in forming a body of beliefs by gathering together all the $<\ldots$ is $\Phi>$ information for which she finds rationally-securing justification for believing $<$ The $\Psi$ is $\Phi>$.

Though it may not be apparent at first glance, this is a radical departure from extant accounts of how description-based aboutness fixing works. Extant accounts treat description-based aboutness-fixing as 'satisfactional': the object the beliefs are about is the satisfier of the aboutness-fixing description. ${ }^{28}$ But in the REFERENCE AND JUSTIFICATION framework, the mechanism of aboutness-fixing for description-based beliefs is not satisfactional. Rather, according to this framework, there is descriptively mediated aboutness where (a) a body of beliefs is justified by using a description to harvest information, and (b) this means of justification converges on some particular thing. In many cases, the thing on which description-based justification converges will also be the satisfier of the relevant description. But description-based aboutness may converge on an object that is not the description's satisfier. And it may fail to converge even when the description is satisfied.

Here are two examples illustrating these possibilities:

Case $6 \mathrm{X}$, the now aged head of a manufacturing company, likes to boast to his underlings about 'the gizmo that started it all', with strong suggestions that he was himself this thing's inventor. The underlings

${ }^{28}$ See for example Evans 1982 pp. 35-6; Campbell 2002 pp 24-5; Jeshion 2004; Goodman 2014. 
introduce a descriptive name 'Gizmo' with aboutness-fixing description $<X$ 's most successful early invention>, and use X's utterances ('Ah, that was the year that the gizmo that started it all really took off' etc.) and the company's financial history to try to work out which of the firm's early patents Gizmo was. (Y suggests that Gizmo was the initial version of the firm's famous self-setting rat trap; $Z$ that it was the jetfuel valve from which the firm made a lot of money in its early days; and so on.) In fact, though there is an invention that enabled the firm to get on its feet, $\mathrm{X}$ was not its inventor: the firm's early patents were all bought for almost nothing from an unworldly individual who died an obscure emeritus professor in a university town.

Case 7 'Geraint the Blue Bard' was used for over a century as a name for the otherwise unidentified author of a series of songs in medieval Welsh, dealing with mythical themes, and employing medieval metres. Rival factions of scholars used evidence from the texts to argue for competing hypotheses about Geraint's life (that he was a minor aristocrat; that he was a priest). However, in 1956 the 'Blue Bard' songs were shown to be the work of notorious nineteenth century forger Edward Williams.

I take it that there are reasonably clear intuitive verdicts about each of these cases. In Case 6, the underlings' 'Gizmo' thoughts are, all along, about the invention they eventually uncover, even though this thing does not satisfy the aboutness-mediating description. In contrast, Case 7 is a case of aboutness-failure, even though the aboutnessmediating description is satisfied. Let us see how the REFERENCE AND JUSTIFICATION framework generates each of these results.

Consider Case 6 first. In this case, the underlings are justifying their 'Gizmo' beliefs by examining the company's financial records and X's memoirs, looking for evidence for $<X$ 's most successful early invention was $\Phi>$ claims. In the informational environment in which the investigation is taking place, pursuit of this justificatory procedure generates a body of beliefs which reliably get right the properties of a specific invention for which X was not in fact responsible. Given REFRENCE AND JUSTIFICATION, the underlings' 'Gizmo' beliefs are about this thing, even though it does not satisfy the description around which their justificatory strategy is based.

Now consider Case 7, and consider how scholars operating before the discovery of the forgery would have justified specific 'Geraint' beliefs. Here is one plausible scenario. Scholar Y gathers, painstakingly, textual evidence for the claims that Geraint never left Wales, and was educated across a wide range of disciplines and up to proficiency in a wide range of languages. She consults authoritative historical sources which say that in ninth century Wales this kind of education was available only at Carmarthen. She concludes that this is where Geraint was educated. Given the level of epistemic responsibility she has exercised, we should allow that Y's conclusion is rational. Yet if Edward Williams in fact was educated at Carmarthen, then as far as the justification for Y's belief is concerned this will be a mere matter of luck! And, given the story of the 'Geraint' ballads, this result generalises: given their justificatory strategy, it would have been a matter of spectacular chance had the scholars ended up with bodies of 'Geraint' beliefs that even approximately matched what Edward Williams was like. So, given REFERENCE AND JUSTIFICATION, the scholar's 'Geraint' beliefs were not about Williams, even though he satisfied the description they associated with the name. ${ }^{29}$

\section{$\S 3$ Objections and replies}

${ }^{29}$ I discuss descriptively mediated aboutness in much more detail in Dickie 2015 ch 6-7. 
The first section of this paper argued for a principle connecting aboutness and what I have called 'justificatory convergence': a body of ordinary beliefs is about the object, if there is one, upon which its proprietary means of justification converges. $\S 2$ showed how this principle both provides a blueprint for a new account of the aboutness of our ordinary beliefs, and promise new avenues for accounts of how our most basic beliefs are justified. This section considers some of the objections and requests for further detail that I anticipate this proposal might provoke. Here are the objections I shall discuss, in the order in which they appear:

1 The objection from the observation that there can be aboutness without justified belief 2 The objection from the appearance of circularity

3 The objection to appeals to intuitions about cases

4 The objection from the incompleteness of the argument for the right-to-left direction of the biconditional

I should stress that I am not attempting a clean sweep of potential objections. Rather, 1-4 are what I take to be the objections that are most urgent and/or illuminating. I have tried to explain and discuss the objections in such a way that each subsection that follows may be read alone, or the set may be read in any order.

\subsection{The objection from the observation that there can be aboutness without justified belief}

The first objection can be brought out using cases like this:

Case 8 You are looking at an ordinary object visible to you only as a speck on the horizon. Since your perceptual link is not delivering any macroscopic property information, you are not forming any $<$ That is $\Phi>$ beliefs. $<$ I wonder what that is $>$ you think.

Case 9 You have been told by someone you have every reason to believe that you have been given a drug which will distort your perceptions of every object you encounter. So, though in fact you are just sitting there looking at an orange on the table in front of you, and receiving a mundane, chemically unenhanced stream of information, you are prudently holding back from forming beliefs by uptake from this information stream. You think to yourself $<$ I wonder what it's really like $>$.

The objector argues as follows. 'Each of these is a case of aboutness. But the current proposal cannot explain why: it explains aboutness only for justified beliefs, so provides no reason to say that the beliefs in Cases 8 and 9 are about anything. The current proposal is, therefore (obviously!) too narrow: it treats aboutness as dependent on a feature (justification) that many beliefs about particulars do not have.'

I shall take it that the observation from which the objection takes its rise is right: in Case 8 you are thinking about the thing on the horizon; in Case 9 about the thing right in front of you. But, contra the objector, this is not a strike against the proposal of $\S 1$. Rather, it forces a clarification: the embedded conditional in REFERENCE AND JUSTIFICATION must be read counterfactually. An aboutness-fixing relation does its aboutness-fixing work by making available a means of justification such that if the 
subject were to form a body of beliefs whose rationality was secured by this means, the subject would be unlucky if these beliefs did not match the object and not merely lucky if they did. This condition may be met regardless of whether the subject actually has any such beliefs. And it is met in both Cases 8 and 9.

In Case 8, you have an attentional link with the object which is not in fact delivering information of the kind that serves as input to our bodies of $<$ that $>$ belief: your attention is locked to the object, but you are not receiving any signal as to its shape, size, colour, or even its distance away. Since there is no such information being delivered, you are not forming any $<$ That is $\Phi>$ beliefs at all, let alone any justified ones. But if the situation were to evolve in such a way that you did start receiving this type of information through the attentional perceptual link - if the distance between you and the object closed, and the attentional link began delivering information of the kind that does trigger formation of $<$ that $>$ beliefs - you would be unlucky if the resulting beliefs did not match the object at the other end of the channel, and not merely lucky if they did.

Similarly, in Case 9, the strong evidence for the claim that your perceptual system is not working reliably leaves you unable to justify beliefs by uptake from the information your attentional perceptual feed is delivering. But, once again, this fact does not undermine the crucial counterfactual: if the barrier to justification were removed without disrupting your attentional link, so that you were in a position to form $<$ that $>$ beliefs justified by uptake from the information the perceptual link delivers, you would be unlucky if the resulting beliefs did not match the attended object, and not merely lucky if they did.

In terms of the telescope analogy from $\S 2$, the point with respect to both cases is just that an aboutness-fixing relation is a relation that secures a kind of focus, and a telescope might be focussed on an object even though it is not in fact currently delivering any information, or even if it is delivering information, but the recipient of the signal is, for whatever reason, holding back from compiling this information into a report.

\subsection{The objection from the appearance of circularity}

The second objection concerns an apparent threat of circularity. To see how the threat arises, consider the following line of thought:

1 A means of belief-formation counts as justification-conferring partly in virtue of tending towards the formation of true beliefs. (This is a version of the claim that justification is truth-conducive, endorsed at pp. 3-5.)

2 A means of forming true beliefs is a means of forming beliefs which tend to match the properties of the object they are about. (This is a version of the connection between aboutness and truth endorsed on p. 5.)

$\mathbf{1}$ and $\mathbf{2}$ entail 3:

3 A means of belief-formation counts as justification-conferring partly in virtue of tending towards the formation of beliefs that tend to match the properties of the object they are about. 
But according to the proposal defended in $\S \S 1-2$, aboutness is itself explained in terms of justificatory convergence:

4 What makes a body of beliefs about a specific object is that it is the object whose properties the associated means of justification tends to get right.

And it is now tempting - or at least, the objector finds it tempting - to put 3 and $\mathbf{4}$ together into the strikingly uninformative $\mathbf{5}$ :

5 What makes a body of beliefs about a specific object is partly the fact that it is the object whose properties tend to be got right by a means of belief formation that tends to get its properties right.

Now, obviously if the proposal reduces to the obviously circular and uninformative 5, it deserves nobody's attention. But fortunately, though it would be a longer job to establish the details, it is relatively easy to bring out where the reduction fails. The proposal might ${ }^{30}$ entail $\mathbf{5}$. But to point out that a proposal entails a circular claim is one thing; to show that it reduces to this claim another. And when we look at $\mathbf{1}$ 5 bearing this difference in mind, it is in fact clear enough where the opportunity to resist the reduction arises. For $\mathbf{5}$ is only a 'partly in virtue of' claim. To suggest that entailing it renders the proposal viciously circular is to ignore a possibility that the $\mathbf{1}-\mathbf{5}$ line of thought leaves wide open: the possibility that there is more to say about what makes our ordinary means of belief-formation justification-conferring than is made explicit at $\mathbf{1}$ and $\mathbf{3}$ and, therefore, more to say about what makes a body of beliefs about a particular than is made explicit by $\mathbf{5}$, and that, when this extra detail is added, the appearance of circularity will fall away.

This response is incomplete without an account of what the 'something more to say' actually is. It is obviously not possible to canvas all potential answers to this question, so I shall rest with sketching my own.

My own view is that the means of belief formation for our ordinary beliefs ultimately owe their justification-conferring status to the fact that they are guided by motivational states of the subject. To see the very general idea, think of what justifies the moves made by a skilled practitioner seeking to achieve some practical goal, for example, a skilled archer shooting at a target. The archer's adjustments as she prepares to let fly are 'justified' in that they are guided by her target-hitting intention, and are reliable generators of this intention's fulfilment. And this is a special case of a kind of positive normative status that applies in general to goal-directed behaviours that are apt to their guiding motivational states: a behaviour is 'justified' in this sense iff it is guided by a motivational state of the subject, and is a reliable means to this state's fulfilment. I suggest that the most basic story about justification for our ordinary beliefs is a 'practical' justification story of this general form: the mind needs to think about things outside itself; formation of bodies of ordinary beliefs in response to incoming

\footnotetext{
${ }^{30}$ This depends on the properties of the $x$ makes $y$ the case relation. What I am about to say does not depend on whether the entailment holds.
} 
information is a behaviour that is guided by this need and - because we are naturally skilled cognitive agents - is a reliable means to this need's fulfilment.

Against this background, we indeed have something more to say about what fixes aboutness than the blatantly circular 5. This 'something more' takes seriously the fact that formation of a body of ordinary beliefs is an information-marshalling activity. Like other activities, this information-marshalling has a goal: we are trying to achieve cognitive focus on things outside the mind. The information-marshalling strategy associated with a specific body of ordinary beliefs has positive normative status, and confers positive normative status on the beliefs it generates, because it is guided by a motivational state of the subject - the mind's need to achieve cognitive focus - and is a reliable means to this need's fulfilment. The body of beliefs is about a specific object iff this means of belief formation in fact is focussed on the object, making the object the unique thing whose properties the subject will tend to get right by forming beliefs justified in this way.

This sketch of how our most basic belief-forming methods confer justification perforce leaves many questions unaddressed. But I hope to have said enough to give someone tempted by the circularity objection pause for thought. ${ }^{31}$

\subsection{The objection from illicit appeals to intuition}

The third objection is that the argument of $\S 1$ is guilty of illicit appeals to intuitions about cases. We can imagine the objector arguing like this: 'There were decades in living philosophical memory when this kind of carry-on - describing cases; declaring intuitive verdicts; treating these verdicts as data; arguing for philosophical theories on the basis that they explain these data - was so commonplace as to be, perhaps, excusable. But it is no longer permissible simply to elevate one's own knee-jerk responses to the status of "ordinary person's intuition". Where data as to this kind of intuition are admissible at all, they must be gathered by scientifically respectable means: by the conduct of experiments which establish which way philosophically uncontaminated intuitions actually lean. This paper repeatedly appeals to purported "intuitive" judgements about cases, without even a gesture towards scientifically respectable evidence for the claim that such intuitions exist. It is, therefore, guilty of methodological crimes with which nobody should expect to get away in these enlightened times. ${ }^{32}$

I take it that, in general, someone using intuitions about cases to do philosophical work has three options - two extremes, and a middle way. The first extreme option is to claim that the purported intuitions in fact do stand to the philosophical proposal as data to theory. Anyone taking this option incurs an obligation to show that the intuitions in fact are sufficiently widespread and theory-uncontaminated to play this role. The second extreme option is to maintain that the philosophical proposal is in fact motivated from

\footnotetext{
${ }^{31}$ I develop this view in much more detail in Ch 3 of Dickie 2015. The view treats achieving cognitive focus as an 'apt performance' in the sense of Sosa 2012 - a performance that is a reliable generator of fulfilment of its guiding motivational state. In the terms proposed by Miracchi 2015 p. 30, this is a 'direct' virtue proposal - cognitive focus is an achievement generated by the subject's competence to achieve it. I am grateful to Thomas Hofweber for his careful criticism of this general treatment of the circularity worry in Hofweber (forthcoming). Dickie (forthcoming) replies.

${ }^{32}$ For wide-raging criticism of appeal to intuitions in philosophy see Cappelen 2012. For recent discussion of such appeals in the theory of reference see Jackman 2009; Genone and Lombrozo 2012.
} 
first principles, and that the discussion of cases has the status of worked examples which illustrate how it is applied. If this is how discussion of cases fits into the overall narrative, the pressure to defend the data-like credentials of verdicts about cases falls away.

Against the background of these extremes, the 'middle way' option emerges as comprising a continuum of intermediate positions, running from the more exampledriven (closer to the first extreme, but with some admixture of 'from first principles' motivation) to the less example-driven (a central role played by 'from first principles' motivation, but purported intuitions about cases accorded some evidential weight).

I intend the discussion of this paper to be located at the less example-driven end of this 'middle way' continuum. I have motivated the REFERENCE AND JUSTIFICATION framework from first principles. But I have also leant a little on intuitive verdicts about cases. Perhaps there are anti-intuition crusaders who will set their faces against placing even this comparatively meagre weight on verdicts about cases without the experimental work necessary to consolidate their status as data. To such a determined opponent, I can only point out the flat-footedness of the core verdicts for which he or she would be demanding experimental validation: the verdicts that the beliefs in Cases $1-3$ are about the orange in front of you, the bearer of 'Aneurin Bevan' as it is used by your informant, and the author of the 'Tremulous Hand' glosses respectively. I have taken it that there is an intuitive sense of 'about' which is reflected in these verdicts, and proposed an account of how this intuitive aboutness is fixed. I defy a reader to claim, hand on heart, that he or she needs an experiment to establish that the intuitive verdicts of aboutness are there to be explained.

\subsection{The objection from the incompleteness of the argument}

The final objection is a reminder that the argument of $\S 1$ is incomplete. Recall the outline of the argument for the right-to-left direction of the REFERENCE AND JUSTIFICATION biconditional:

1 Suppose that $\mathrm{S}$ is maintaining a body of ordinary beliefs whose proprietary means of justification converges on $o$, so that if $\mathrm{S}$ forms only $<\alpha$ is $\Phi>$ beliefs whose rationality is secured by this means, either $o$ is $\Phi$, or the situation is rationally irrelevant.

2 There are three cases.

(a) The beliefs are about some $o *$ other than $o$.

(b) They are about $o$.

(c) They are about nothing.

3 The beliefs are not about some $o^{*}$ other than $o$.

4 The beliefs are not about nothing.

So

5 The beliefs are about $o$.

Therefore 
6 Where proprietary justification for a body of ordinary beliefs converges on $o$, the beliefs are about $o$.

The discussion of $\S 1$ left the argument for $\mathbf{4}$ in rough and ready form: I said only that to suppose $\mathbf{4}$ false is to suppose that there is some extra condition on aboutness above and beyond justificatory convergence (we already know that justificatory convergence is a necessary condition on aboutness - this is established by the argument of pp 5-6) and it is hard to see what explanatory role this condition might play.

To reach a full-dress version of this line of thought, we shall ask what the extra condition might be. Let us suppose, again, that $\mathbf{4}$ is false, and pay closer attention to the details of what follows:

(i) Suppose that $\mathbf{4}$ is false: the beliefs are about nothing.

(ii) Suppose also that for some $\Phi, \mathrm{S}$ has a rational $<\alpha$ is $\Phi>$ belief.

Since the belief is about nothing, it is not true. But TRUTH AND JUSTIFICATION entails that where a rational belief is not true, the subject's mistake traces to some rationalirrelevance-producing factor. So (i) and (ii) entail (iii):

(iii) The actual situation is rationally irrelevant to formation of the belief: it is a situation in which the belief fails to be true in virtue of the presence of some factor against which the subject is not rationally required to be on his or her guard.

Having arrived at (iii), it is tempting to try to argue that, given 1, there can be no such factor, and that the supposition at (i) has, therefore, been reduced to absurdity.

Unfortunately, this tempting strategy does not stand up to scrutiny. For one way for a circumstance to be rationally irrelevant is for it to involve hidden aboutness-failure. So to push through the tempting line of thought, we would already need to be supposing that the situation as described at $\mathbf{1}$ does not involve aboutness failure, which is what we are trying to establish.

However, though this tempting line of thought must be abandoned, ordinary beliefs have a property that is going to let us have something nearby: ordinary beliefs are existentially committing; if it is rational for a subject to hold an ordinary belief, it is also rational for the subject to hold the corresponding existential generalisation. (This is just the claim that if it is rational to believe $\langle$ That is $\Phi>,\langle\mathrm{NN}$ is $\Phi>$, or $<$ Tremulous Hand is $\Phi>$, it is rational to believe $<$ Something is $\Phi>$ too. $)^{33}$ This claim about the relationship between ordinary beliefs and their existential generalisations can be reformulated as a claim about rational relevance:

(iv) If a situation is irrelevant to formation of the belief that $\langle\alpha$ is $\Phi>$, it is also irrelevant to formation of the corresponding belief that $<$ Something is $\Phi>$.

\footnotetext{
${ }^{33}$ Note that this is a claim about ordinary beliefs only. It leaves it open that there might be $<\ldots$ is $\Phi>$ beliefs - for example, beliefs 'about' fictional characters - which are not existentially committing.
} 
(Suppose that (iv) is false. Then, focussing on the perceptual demonstrative case, a stream of justification could make it rational to believe $<$ That is $\Phi>$ (eliminating all relevant belief-not-true circumstances), while leaving it irrational to believe $<$ Something is $\Phi>$ (because there are circumstances where nothing is $\Phi$ that must be ruled out if it is to be rational to believe $<$ Something is $\Phi>$ but which did not have to be ruled out to secure the rationality of the <That is $\Phi>$ belief).)

Combining (i)-(iv) we get (v):

(v) If justification converges but aboutness fails, then, for all $\Phi$, if $\mathrm{S}$ has a rational belief that $<\alpha$ is $\Phi>$, the situation is irrelevant to the formation of the belief that $<$ Something is $\Phi>$.

And now we can ask the question we wanted to ask at (iii) but had to drop for fear of circularity: what might the factor generating rational irrelevance be?

Now, a rational belief that $<$ Something is $\Phi>$ is a belief formed in a way that manifests competence at forming such beliefs (a belief formed in such a way that, unless the situation involves some rational-irrelevance-generating factor, it will count as knowledge $)^{34}$. If such a competence-manifesting belief does not count as knowledge, this can only be because the situation involves some factor that renders the test for $\Phi$ instantiation that the subject is deploying insensitive, so that, though in general this test tends to get things right, in the situation in which the belief is formed a positive result with respect to this test does not indicate $\Phi$-instantiation at all.

In general, there are two kinds of factor that might be responsible for this kind of insensitivity in an otherwise reliable test, one more unusual than the other. In the less unusual kind of case, the test is getting it right with respect to the presence of an object (a potential $\Phi$-instantiator), but wrong with respect to this object's $\Phi$-ness or not. (For example, this is what happens when you see an object through a distorting window, seeing a round thing as square.) In the more unusual case, the test is giving a positive result for $\Phi$-instantiation when there is not an object there at all. (For example, imagine that your visual system is producing an experience indistinguishable by you from an experience of a cubical thing, when in fact the appearance of cubicality is cooked up out of fence-wires crossing in the foreground against shadows in the forest behind.) But it is built into the description of the situation at $\mathbf{1}$ that it is not the second, very unusual, kind of factor that is at issue. 1 stipulates that the tests for property instantiation you are deploying are responsive to the properties of some particular object: given $\mathbf{1}$, if there is a concealed factor leading S astray as to whether anything is $\Phi$, it is not a factor to do with whether there is anything out there: $\mathrm{S}$ is deploying a test for $\Phi$-instantiation which is (rightly) picking up the presence of an object (a potential $\Phi$-instantiator), but giving a false positive as to this thing's $\Phi$-ness. So we can move from (v) to

(vi) If justification converges on $o$, but aboutness fails then, for all $\Phi$, if $\mathrm{S}$ has a rational belief that $<\alpha$ is $\Phi>$, the situation involves a factor that renders the test for $\Phi$ instantiation $\mathrm{S}$ is deploying insensitive to whether $o$ is $\Phi$.

\footnotetext{
${ }^{34}$ I intend 'manifest' here in the sense of Sosa 2015 ch 2.
} 
And now we can use (vi) to generate an account of the extra condition on aboutness which must be met for a case of justificatory convergence to be a case of aboutness too: the extra condition is just the non-obtaining of the condition under which a case of justificatory convergence is a case of aboutness failure. A case of justificatory convergence is a case of aboutness failure only if there is no $\Phi$ such that (a) the subject has proprietary rationality-securing justification for believing $\langle\alpha$ is $\Phi>$, and (b) the test for $\Phi$-instantiation that generates this justification is in fact getting $o$ 's $\Phi$-ness right. So a case of justificatory convergence is a case of aboutness iff there is some $\Phi$ for which (a) and (b) are met. So we have arrived at (vii):

(vii) A body of ordinary beliefs is about the object, if there is one, upon which its justification converges as long as the proprietary means of justification is also providing the subject with at least one rational belief that matches what this object is like.

Now, this extra condition is not, strictly speaking, absurd. But I take it that it is obviously hopeless. ${ }^{35}$ What possible virtue could there be to the suggestion that thinking about an ordinary object requires knowing one - any one - of its macroscopic properties? None except from the point of view of an inconvincible opponent looking for any way to wiggle out of the conclusion of $\S 1$ : the conclusion that there is aboutness iff there is justificatory convergence.

\section{Conclusion}

The aim of this paper has been to establish a principle connecting two fields of inquiry: the 'aboutness fixing' part of the theory of reference, and traditional ' $S$ knows that p' epistemology. According to the framework for accounts of aboutness-fixing built around this principle, the aboutness of our ordinary beliefs is a kind of focus: a body of ordinary beliefs is about the object, if there is one, upon which its characteristic means of justification converges; the object whose properties the subject will be unlucky to get wrong and not merely lucky to get right in forming beliefs whose rationality is secured in this way. $\S 1$ argued for this principle. In the broadest terms, the suggestion was that the principle brings out the significance for accounts of aboutness-fixing of the fact that justification is truth-conducive. $\S 2$ showed how the principle offers both a new blueprint for accounts of aboutness-fixing for our ordinary beliefs, and a new source of considerations to bring to bear on traditional epistemological debates. $\S 3$ considered objections and replies. Though I do not take myself to have answered all the questions the reader might have about the proposal I have made, I do hope to have said enough to render the claim I set out to defend not implausible: there is an essential connection between epistemology and the theory of reference; a connection through which influence flows irresistibly from each field of inquiry to the other.

\footnotetext{
${ }^{35}$ It is important to distinguish the italicized condition in (vii) from the less implausible claim that thought about an object requires a rational belief that gets some special one of its properties right: (vii) makes knowing just one, any one, of an object's ordinary macroscopic properties a necessary condition on thinking about it.
} 


\section{REFERENCES}

Bach, Kent 2002 'Giorgione was so called because of his name' Philosophical Perspectives 16: Language and Mind pp. 73-104.

Bach, Kent 2006 'What does it take to refer?' in E. Lepore and B. C. Smith (eds.) The Oxford Handbook of the Philosophy of Language Oxford: Oxford University Press.

Bach, Kent 2010 'Getting a thing into a thought' in Jeshion (ed.) 2010.

Benacerraf, Paul. 1973 'Mathematical Truth' The Journal of Philosophy vol LXX no 8 1973 pp. 661-679.

Bratman, Michael. 1987 Intentions, Plans, and Practical Reason Stanford CA: CSLI

Campbell, John. 1999. 'Immunity to Error Through Misidentification and the Meaning of a Referring Term’ Philosophical Topics 26 pp89-94.

Campbell, John. 2002 Reference and Consciousness Oxford: Oxford University Press

Comesana, Juan. 2010 ‘Evidentialist Reliabilism’ Noûs 44:4 (2010), 571-600.

Conee, Earl and Richard Feldman 1998 'The Generality Problem for Reliabilism' Philosophical Studies 89 (1) pp. 1-29.

Dickie, Imogen 2015 Fixing Reference. Oxford: Oxford University Press.

Dickie, Imogen. (forthcoming) 'Replies to Heck, Hofweber, and Ninan' Philosophy and Phenomenological Research.

Duhem, Pierre 1914 The Aim and Structure of Physical Theory trans. P. Wiener. Princeton: Princeton University Press 1954.

Dummett, Michael. 1978 'Truth' in Dummett Truth and Other Enigmas Cambridge: Harvard University Press.

Evans, Gareth. 1982 The Varieties of Reference. Oxford: Oxford University Press.

Genone, James and Tania Lombrozo 2012 'Concept possession, experimental semantics, and hybrid theories of reference' Philosophical Psychology 25 (5) pp1-26. 
Goodman, Rachel. 2015 'Against the Mental Files Conception of Singular Thought' Review of Philosophy and Psychology

Gopnik, Alison; Thomas L. Griffiths; and Christopher G. Lucas 2015 'When Younger Learners Can Be Better (or at Least More Open-Minded) Than Older Ones’ Current Directions in Psychological Science Vol 24\#2 pp87-92.

Hofweber, Thomas. (forthcoming) 'Dickie's epistemic theory of reference' Philosophy and Phenomenological Research

Jackman, Henry. 2009. 'Semantic Intuitions, Conceptual Analysis, and Cross-Cultural Variation’ Philosophical Studies 146 (2) pp 159-77,

Jeshion, Robin 'Singular Thought: Acquaintance, Semantic Instrumentalism, and Cognitivism' in Jeshion (ed.) 2010.

Jeshion, Robin (ed.) 2010 New Essays on Singular Thought. Oxford: Oxford University Press.

Kripke, Saul 1980 Naming and Necessity Cambridge MA: Harvard University Press

Kripke, Saul 1977 'Speaker's Reference and Semantic Reference' in Studies in the Philosophy of Language ed. P. French, T. Ueling, and H. Wettstein. Minneapolis MN: University of Minnesota Press.

Lewis, David. 1999 'Elusive Knowledge' in Lewis Papers in Metaphysics and Epistemology Cambridge: Cambridge University Press.

Miracchi, Lisa. 2015 'Competence to Know’ Philosophical Studies 172: pp. 29-56.

Palmer, Steven. 1999 Vision Science Cambridge MA: MIT Press.

Putnam, Hilary. 1975. "The Meaning of 'Meaning"”, Minnesota Studies in the Philosophy of Science, 7: 215-271.

Pylyshyn, Zenon. 2003 Seeing and Visualising: It's not what you Think Cambridge MA: MIT Press

Recanati, Francois 2010 'Singular Thought: In Defence of Acquaintance' in Jeshion (ed.) 2010.

Recanati, Francois 2012 Mental Files Oxford: Oxford University Press

Russell, Bertrand. 1912. The Problems of Philosophy Oxford: Oxford University Press.

Russell, Bertrand 1956 Logic and Knowledge ed. R. C. Marsh. London: Routledge. 
Russell, Bertrand 1956a 'On Denoting' in Russell 1956

Russell, Bertrand 1956b 'The Philosophy of Logical Atomism' in Russell 1956

Scholl, Brian. (ed.) 2002 Objects and Attention Cambridge MA: MIT Press.

Sosa, Ernest. 1999. 'How to Defeat Opposition to Moore' Noûs, (Supplement:

Philosophical Perspectives, 13, Epistemology) 33: 141-153.

Sosa, Ernest. 2015 Judgment and Agency Oxford: Oxford University Press

Strawson, Peter. 1959 Individuals. London: Methuen.

Williamson, Timothy. 2000. Knowledge and its Limits. Oxford: Oxford University Press. 